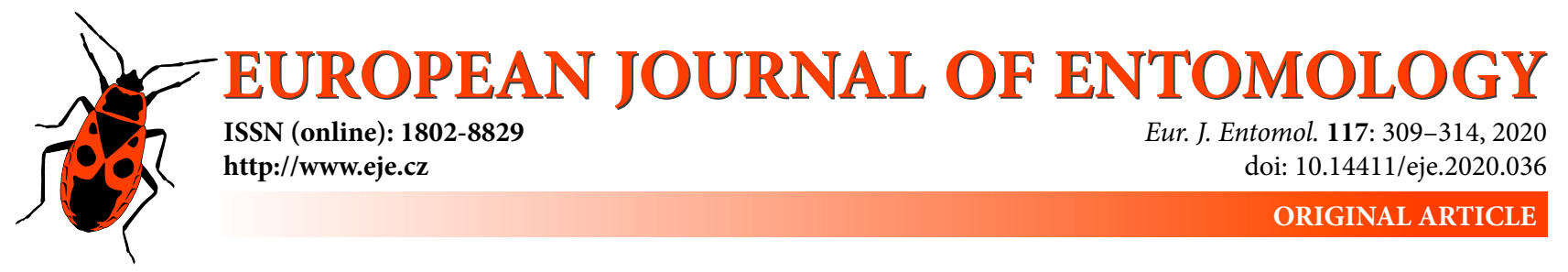

\title{
What determines the occurrence of fertilized females in hibernating populations of Pyrrhocoris apterus (Heteroptera: Pyrrhocoridae) in Central Europe?
}

\author{
ALOIS HONĚK and ZDENKA MARTINKOVÁ \\ Crop Research Institute, Drnovska 507, 16106 Praha 6 - Ruzyne, Czech Republic; e-mails: honek@vurv.cz, \\ martinkova@vurv.cz
}

Key words. Heteroptera, Pyrrhocoridae, Pyrrhocoris apterus, oviposition, egg, fertlization, hibernation, voltinism, population, climate warming, Central Europe

\begin{abstract}
The current climate warming is associated with the development of a second generation in populations of species such as Pyrrhocoris apterus (L.) (Heteroptera: Pyrrhocoridae), which, in Central Europe, were univoltine in the 1980s. Females of the first generation that develop in spring either enter diapause immediately following the adult moult or after a period of oviposition that gives rise to a second generation. In 2005-2010, in overwintering populations, $3 \pm 0.6 \%$ of females were fertilized. We explored the possibility that the females that overwintered in a fertilized state were those that had oviposited in the previous season. To test this hypothesis, we reared females of the first generation that moulted to the adult stage in June-August under natural conditions. For these females, we recorded oviposition, mortality and overwintering in the fertilized state. In 2004-2007, the majority $(78 \%)$ of the first-generation females that oviposited in summer also died before winter and the rest entered dormancy and overwintered. Most of the overwintering females that had laid eggs before overwintering were fertilized. However, the majority $(63 \%)$ of females that overwintered in the fertilized state had not laid eggs in the previous season; they only copulated and stored the sperm until the next spring. The presence of fertilized females in a hibernating population thus indicates pre-winter sexual activity but not the percentage of first-generation females that oviposit before overwintering.
\end{abstract}

\section{INTRODUCTION}

The current climate changes, especially global warming, might have far-reaching effects on insect species that can respond to increasing temperatures in several ways. Among other important effects are changes in species life history, particularly the number of generations per year (Kiritani, 2006, 2013; Musolin \& Saulich, 2012). The expected increase in the number of generations due to climate warming has been reported recently for some Coleoptera (Fleischer et al., 2016; Pineau et al., 2017), Hemiptera (Hulle et al., 2008) and Lepidoptera (Altermatt, 2010; Pavan et al. 2013).

An example of a univoltine species in which the Central European populations are reported to produce a second generation (but with a low percentage of fertilized females) is Pyrrhocoris apterus (L.) (Heteroptera: Pyrrhocoridae) (Honek et al., 2020). This medium-sized terrestrial species overwinters as an adult. In early spring, overwintered adults make full use of their thermoregulatory abilities and raise their body temperature above ambient temperatures by basking in the sun (Honek \& Martinkova, 2019). Starting in April, the overwintered females copulate and lay eggs (Honek et al., 2019). The larvae develop and moult into adults starting in June (Honek, 1981). The majority of newly emerged adults enter diapause without reproducing throughout summer and early autumn before hibernating. In recent years, in some populations, a small percentage of the newly emerged adults reproduce and produce a partial second generation before overwintering (Honek et al., 2020). It is likely that the development of this second generation is made possible by climate warming.

Most of the earlier authors considered P. apterus in Central and Western Europe to be univoltine, for example, in France (Pouvreau, 1963; Pluot, 1978), Germany (Mayer, 1874; Schwoerbel, 1956; Tischler, 1959) and the Czech Republic (Hodek, 1968). However, Hodek (1971) reports a female ovipositing under short day conditions in a sample collected in early August. This finding could indicate the existence of a partial second generation. Later, Socha \& Sula (1992) established that females from wild populations of P. apterus that moulted into adults in July and August have, after transfer to long-day laboratory conditions, a pre-oviposition period similar in length to that of non-diapausing females. Thus, it is clear that females that moult in early summer may potentially become fertile, oviposit and establish a second generation. However, it was 
not clear whether or how often a second generation occurs in local populations and individual years. The existence of reproduction before overwintering of first generation of females was supported by demonstrating that some of the overwintering females had been fertilized prior to hibernating (Socha, 2010). The presence of fertilized females in hibernating populations was considered to be evidence that some first-generation females oviposited. These females were assumed to produce a partial second generation. It was assumed that these females entered diapause later and overwintered with other diapausing females. These females remained fertilized throughout the winter because they had an unused sperm supply remaining from the previous breeding season. The existence of a partial second generation in some populations of $P$. apterus in Central Europe is reported by Honek et al. (2020). Therefore, it is of interest to examine whether the presence of fertilized females in hibernating populations is indeed a consequence of the fact that these females oviposited in the previous season.

In this study we determined the population processes that lead to the presence of fertilized females in overwintering populations. We first reviewed the observations of Socha (2010) and then determined the percentage of overwintering fertilized females in local populations in a geographical area located $\sim 130 \mathrm{~km}$ away from the area studied by Socha (2010). After which, we reared females of the first generation that moulted into adults in June-August under natural conditions and established whether they laid eggs or entered diapause immediately. These females were kept at natural photoperiods and temperatures until the end of winter, when we determined whether they had hibernated in a fertilized or non-fertilized condition. We tested the hypothesis that the percentage of fertilized females in the overwintering population is similar to the percentage of females that oviposited prior to hibernation.

\section{MATERIALS AND METHODS}

\section{Rearing}

In all experiments described below, male/female pairs or single females were kept in transparent plastic cups $\left(20 \mathrm{~cm}^{2}\right.$ bottom area) sealed with nylon fabric and mass reared in plastic boxes (600 $\mathrm{cm}^{2}$ bottom area) covered with perforated lids. These bugs were supplied with excess linden seed (Tilia cordata Mill.) spread over the bottoms of the rearing cups and boxes and water on a moist piece of cellulose. A piece of folded filter paper increased the area available for climbing.

\section{Establishing the percentage of fertilized females in natural overwintering populations}

To establish the percentage of fertilized females in natural populations, overwintering adults were sampled in 2005-2010 at 12 localities in central Bohemia, situated between $49.9^{\circ}$ and $50.1^{\circ} \mathrm{N}$ and $14.0^{\circ}$ and $15.3^{\circ} \mathrm{E}$ at altitudes of $210-410 \mathrm{~m}$ a.s.l. (Table 1). At four localities, they were sampled in 3-5 subsequent years giving a total of 24 samples of overwintering populations. All samples were collected in late winter before the start of spring mating activity. To determine the percentage of overwintering fertilized females in wild populations, single females were isolated immediately after sampling, placed in rearing cups and maintained at a 16L : 8D photoperiod and $25^{\circ} \mathrm{C}$ until they laid eggs or died. Females that lived for 40 days without laying eggs were discarded and considered to be non-ovipositing.

Table 1. The percentage of overwintering fertilized females in populations in central Bohemia. The table indicates the locality of the site sampled, its geographic position [coordinates ( $N, E)$ and altitude ( $\mathrm{m}$ a.s.I.)], year and date sampled, total number ( $\mathrm{N}$ ) of females that oviposited after transfer to the laboratory, number of unfertilized females and number and percentage (\%) of fertilized females.

\begin{tabular}{|c|c|c|c|c|c|c|c|c|}
\hline \multirow[b]{2}{*}{ Locality } & \multicolumn{3}{|c|}{ Geographic position } & \multicolumn{2}{|c|}{ When sampled } & \multicolumn{3}{|c|}{ Females } \\
\hline & ${ }^{\circ} \mathrm{N}$ & ${ }^{\circ} \mathrm{E}$ & Altitude & Year & Day & $\begin{array}{c}\text { Total } \\
\mathrm{N}\end{array}$ & $\begin{array}{c}\text { Unfertilized } \\
\mathrm{N}\end{array}$ & $\begin{array}{c}\text { Fertilized } \\
\mathrm{N}(\%)\end{array}$ \\
\hline Bořetice & 49.963 & 15.175 & 340 & 2007 & 24-Feb & 50 & 47 & $3(6.0)$ \\
\hline Hlízov & 49.982 & 15.293 & 210 & 2007 & 24-Feb & 35 & 35 & $0(0.0)$ \\
\hline \multirow[t]{4}{*}{ Karlštejn } & 49.932 & 14.174 & 230 & 2005 & 15-Mar & 67 & 66 & $1(1.5)$ \\
\hline & & & & 2007 & 03-Mar & 63 & 59 & $4(6.3)$ \\
\hline & & & & 2008 & 07-Mar & 25 & 23 & $2(8.0)$ \\
\hline & & & & 2010 & 03-Mar & 104 & 102 & $2(1.9)$ \\
\hline Klánovice & 50.09 & 14.667 & 250 & 2005 & 13-Mar & 46 & 45 & $1(2.2)$ \\
\hline Koloděje & 50.06 & 14.639 & 280 & 2005 & 13-Mar & 38 & 38 & $0(0.0)$ \\
\hline \multirow[t]{4}{*}{ Lounín } & 49.908 & 14.012 & 410 & 2005 & 15-Mar & 57 & 54 & $3(5.3)$ \\
\hline & & & & 2007 & 03-Mar & 69 & 67 & $2(2.9)$ \\
\hline & & & & 2008 & 07-Mar & 41 & 39 & $2(4.9)$ \\
\hline & & & & 2010 & 03-Mar & 57 & 57 & $0(0.0)$ \\
\hline \multirow[t]{3}{*}{ Mokropsy } & 49.946 & 14.33 & 210 & 2005 & 15-Mar & 54 & 54 & $0(0.0)$ \\
\hline & & & & 2007 & 03-Mar & 30 & 28 & $2(6.7)$ \\
\hline & & & & 2010 & 03-Mar & 104 & 101 & $3(2.9)$ \\
\hline Pašinka & 49.996 & 15.186 & 260 & 2007 & 24-Feb & 32 & 31 & $1(3.1)$ \\
\hline Prague - Dejvice & 50.101 & 14.393 & 220 & 2005 & 15-Mar & 58 & 58 & $0(0.0)$ \\
\hline \multirow[t]{5}{*}{ Prague - Ruzyne } & 50.087 & 14.307 & 340 & 2005 & 17-Mar & 69 & 68 & $1(1.4)$ \\
\hline & & & & 2007 & 01-Mar & 63 & 58 & $5(7.9)$ \\
\hline & & & & 2008 & 05-Mar & 75 & 74 & $1(1.3)$ \\
\hline & & & & 2009 & 28-Mar & 86 & 82 & $4(4.7)$ \\
\hline & & & & 2010 & 02-Mar & 93 & 87 & $6(6.5)$ \\
\hline Prague - Vokovice & 50.093 & 14.327 & 320 & 2005 & 13-Feb & 32 & 32 & $0(0.0)$ \\
\hline Zdice & 49.908 & 13.983 & 260 & 2005 & 15-Mar & 51 & 48 & $3(5.9)$ \\
\hline Total & & & & & & 1399 & 1353 & $46(3.4 \pm 0.56)$ \\
\hline
\end{tabular}




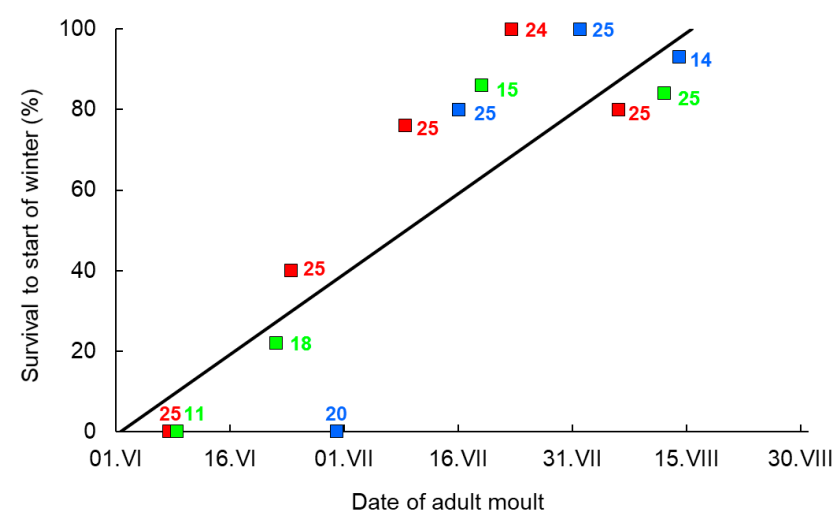

Fig. 1. The percentage of females in particular cohorts that survived until the beginning of the overwintering period on 15 October ( $\square$ ) plotted against the date of cohort establishment (the date of the adult moult of the females). The numbers associated with the points indicate the initial number of individuals in a cohort. The colours of the points indicate the year of the experiment: 2004 - red, 2006 - blue, 2007 - green. Regression (arcsine-transformed data): $\mathrm{n}=13, \mathrm{a}=-6.420, \mathrm{~b}=0.0418, \mathrm{R}^{2}=0.705, \mathrm{~F}_{1,12}=26.297, \mathrm{P}<0.001$

\section{Survival and overwintering of first-generation females}

Larvae of P. apterus were sampled at Prague - Liboc (in 2004; $50.0929^{\circ} \mathrm{N}, 14.3269^{\circ} \mathrm{E}, 320 \mathrm{~m}$ a.s.1.) and Prague - Ruzyne (in 2006 and $2007 ; 50.0868^{\circ} \mathrm{N}, 14.3069^{\circ} \mathrm{E}, 340 \mathrm{~m}$ a.s.1.), 4 or 5 times each year from June to August. The larvae collected were immediately put in mass-rearing boxes and kept in a room with a temperature of $26 \pm 1{ }^{\circ} \mathrm{C}$ and a natural outdoor photoperiod. Experiments were on adults that moulted within 1 day of sampling. These groups of adults of the same age were called "cohorts" and were designated by the date they moulted into adults. From each cohort, 25 male/female pairs were established (or fewer when the number of moulted females was lower). Each pair was placed in a separate cup, and the remaining males were held in the mass-rearing boxes to replace paired males that died before the females. The rearing cups were immediately placed in an open shelter with a natural photoperiod and temperature. The copulation, oviposition and survival of paired females were recorded at 2-4 day intervals until 15 October, when females that were still alive were considered to have survived to the overwintering period. The males were removed from male/female pairs, and individual females, each placed in an individual cup, were kept in an open shelter under natural photoperiod and temperature conditions. On 15 February, the females were transferred to laboratory conditions $\left(16 \mathrm{~L}: 8 \mathrm{D}\right.$ photoperiod and $\left.25^{\circ} \mathrm{C}\right)$ to terminate their dormancy. After the transfer, the females were checked at 2-3 day intervals until oviposition or death. The egg batches from each female were kept in separate Petri dishes $(2.5 \mathrm{~cm}$ diameter $)$ at $25^{\circ} \mathrm{C}$ until they hatched, which was a sign that the female had hibernated in a fertilized state. Unhatched eggs were considered unfertilized and discarded after 14 days.

\section{Data analysis}

The data are presented as arithmetic means and standard errors. The difference in the percentage of fertilized females in the overwintering populations in southern Bohemia (Socha, 2010) and in central Bohemia was tested using a t-test, with the percentage of fertilized females in a particular population as the response variable and the region of origin (southern Bohemia vs. central Bohemia) as the factor. The linear regression $y=a+b x$, where $y$ is (i) the percentage of the females that survived in each cohort until 15 October and (ii) the percentage of females hibernating in a fertilized state that laid fertilized eggs after 15 February, and $\mathrm{x}$ is

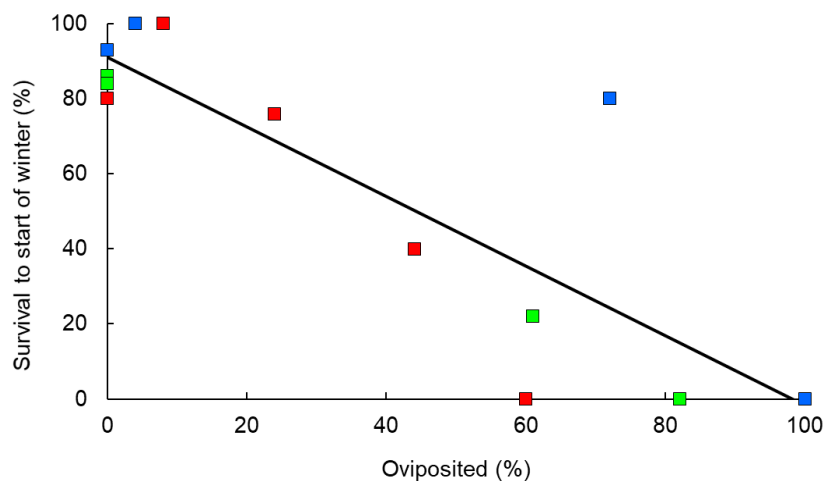

Fig. 2. The percentage of females in particular cohorts that survived until the beginning of the overwintering period on 15 October $(\square)$ plotted against the percentage of females that oviposited in that cohort. The colours of the points indicate the year of the experiment: 2004 - red, 2006 - blue, 2007 - green. Regression (arcsinetransformed data): $n=13, a=2.710, b=-0.883, R^{2}=0.643, F_{1.12}$ $=19.847, \mathrm{P}<0.001$

the date (Julian day) of cohort establishment (date of adult moult of the females). The correlation between the percentage of ovipositing females in a cohort and the percentage mortality in this cohort during the pre-hibernation period was calculated as the percentage of females that survived in each cohort until 15 October. These calculations were made using arcsine-transformed percentage data and SigmaStat software (Systat Software, 2006).

\section{RESULTS}

\section{Fertilized females in natural overwintering populations}

In wild populations in central Bohemia, there was widespread overwintering of a low percentage of fertilized $P$. apterus females (Table 1). In 24 samples taken from 12 populations over 6 years, fertilized females were present in $18(75 \%)$ samples. In samples where fertilized females were present, the fertilized females made up $1.3-8.0 \%$ of the population; the average percentage of fertilized females in the samples (including the six where fertilized females were not found) was $3.4 \pm 0.56 \%$ (Table 1).

\section{Survival of first-generation females in experimental cohorts}

In 13 cohorts of females that moulted into adults from June to August 2004-2008, the percentage of females that survived to the start of the overwintering period (15 October) increased with the course of the vegetative season, from an average of $12 \pm 8.1 \%$ in June to $86 \pm 5.3 \%$ in July and $89 \pm 4.5 \%$ in August (Fig. 1). The mortality in the prehibernation period was positively correlated with the percentage of ovipositing females in a cohort (Fig. 2). A large percentage of ovipositing females [in total, 73 (78\%) of 93 ovipositing females] died before the onset of hibernation (Table 2). In three cohorts in which they all died before hibernation (established between 8 and 30 June) ovipositing females made up $80-93 \%$ of the cohort. In four cohorts in which females did not oviposit in summer (established between 19 July and 12 August), 80-93\% of the females survived until the start of hibernation. Of the first generation ovipositing females only $22 \%$ survived until the beginning 
Table 2. Mortality and survival until the beginning of the winter period (15 October) of females belonging to cohorts established (moulted to the adult stage) in June, July and August; laying eggs (ovipositing) and not laying eggs after becoming adult (non-ovipositing). The table presents the data shown by cohort in Fig. 1.

\begin{tabular}{lccccccc}
\hline & \multicolumn{3}{c}{ Ovipositing } & & \multicolumn{3}{c}{ Non-ovipositing } \\
\cline { 2 - 3 } \cline { 7 - 8 } & Total & Dead & Survived & & Total & Dead & Survived \\
& $\mathrm{N}$ & $\mathrm{N}(\%)$ & $\mathrm{N}(\%)$ & & $\mathrm{N}$ & $\mathrm{N}(\%)$ & $\mathrm{N}(\%)$ \\
\hline June & 66 & $60(91)$ & $6(9)$ & & 33 & $30(91)$ & $3(9)$ \\
July & 26 & $13(50)$ & $13(50)$ & & 63 & $9(14)$ & $54(86)$ \\
August & 1 & $0(0)$ & $1(100)$ & & 88 & $11(12)$ & $77(88)$ \\
\hline Total & 93 & $73(78)$ & $20(22)$ & 184 & $50(27)$ & $134(73)$ \\
\hline
\end{tabular}

of winter (Table 2). The mortality of ovipositing females was high in the June cohorts (91\%) and lower in the cohorts established in July (50\%). Of the non-ovipositing females, $73 \%$ survived to the beginning of winter (Table 2). Thus, a large percentage of first-generation females that oviposited immediately after reaching the adult stage died before the onset of winter.

\section{Fertilized females in experimental cohorts that survived overwinter}

The percentage of fertilized females in the experimental cohorts that survived overwinter until 15 February decreased with increase in the date of cohort establishment (Fig. 3). The trend in the decline in the percentage of fertilized females with increase in the date of cohort establishment is clear, although a large percentage of the ovipositing females died before the start of overwintering. Of 100 experimental females that survived from all experimental cohorts until the artificial termination of hibernation on 15 February, approximately one-quarter (24 females) were fertilized. Nine of these females ( $38 \%$ of fertilized females) oviposited during the summer period before overwintering, while 15 females ( $62 \%$ of fertilized females) did not lay eggs before overwintering (Table 3 ). The latter females mated during the pre-hibernation period; however, only a few were actually observed in copula. Three-quarters of the females that survived overwinter ( $76 \%$ of the total) did not lay fertilized eggs. Of these females, 73 (96\% of unfertilized females) did not oviposit before overwintering. Surprisingly, three females (4\% of unfertilized females) that laid eggs in the previous season turned out to be unfertilized at the end of the overwintering period.

Table 3. The number of females that oviposited and did not oviposit before the beginning of the winter period (rows) that laid fertilized eggs after overwintering (i.e., overwintered in a fertilized state) and did not lay fertilized eggs after overwintering (i.e., did not overwinter in a fertilized state) (columns). The table includes 100 females from all the cohorts that survived until 15 February.

\begin{tabular}{lccc}
\hline \multirow{2}{*}{$\begin{array}{l}\text { Oviposited before } \\
\text { overwintering }\end{array}$} & \multicolumn{3}{c}{ Laid fertilized eggs after overwintering } \\
\cline { 2 - 4 } & Yes & No & Total \\
\hline Yes & 9 & 3 & 12 \\
No & 15 & 73 & 88 \\
\hline Total & 24 & 76 & 100 \\
\hline
\end{tabular}

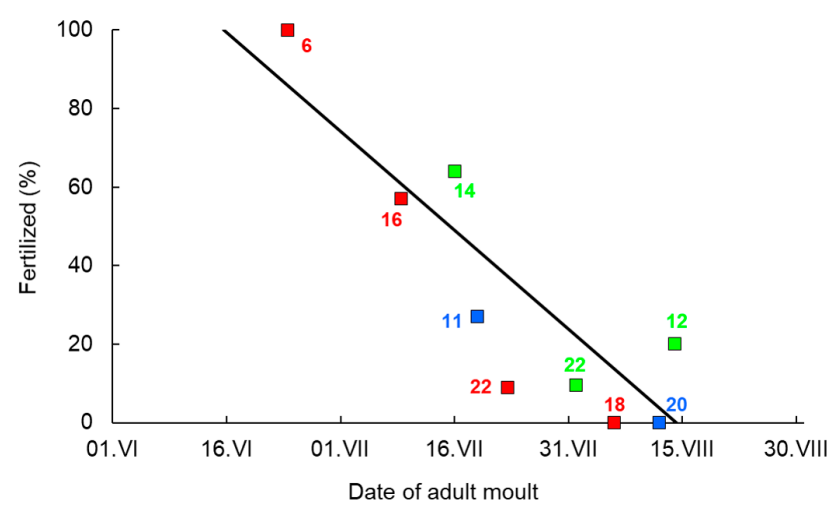

Fig. 3. The percentage of fertilized females in each cohort that survived until the end of the hibernation period (15 February) and oviposited ( $\square$ ) regressed on the date of cohort establishment (the date of the adult moult of the females). The numbers associated with the points indicate the initial number of individuals in the sample at the start of the hibernation period. The colours of the points indicate the year of the experiment: 2004 - red, 2006 - blue, 2007 - green. Regression (arcsine-transformed data): $n=9, a=11.975$, $\mathrm{b}=-0.0527, \mathrm{R}^{2}=0.772, \mathrm{~F}_{1,8}=24.607, \mathrm{P}=0.002$.

\section{DISCUSSION}

\section{Overwintering of fertilized females in the wild}

Fertilized overwintering females were found both in populations in southern (Socha, 2010) and central Bohemia. The period during which females of the first generation oviposit widens with increasing temperatures (Honek et al., 2020). It can therefore be expected that the percentage of fertilized females in hibernating populations is influenced by the climate in the area of their origin. The localities sampled in southern and central Bohemia are separated by a distance of approximately $130 \mathrm{~km}$. The region in southern Bohemia is situated at an altitude approximately $250 \mathrm{~m}$ higher than that in central Bohemia and is therefore cooler. The average annual temperature $\left(7^{\circ} \mathrm{C}\right.$ in the area of origin of the south Bohemian populations and $8-9^{\circ} \mathrm{C}$ in the area of origin of the central Bohemian populations), the average temperature of the vegetative season (April-November; $13^{\circ} \mathrm{C}$ and $14-15^{\circ} \mathrm{C}$, respectively) and the average temperature in each of the individual months are $1-1.5^{\circ} \mathrm{C}$ lower in southern Bohemia than in central Bohemia (Vesecky et al., 1958; Matejka 2019). Despite this difference, the percentages of fertilized overwintering females in southern Bohemia $(3.4 \pm 0.82 \%, \mathrm{n}=9)$ and in central Bohemia $(3.4 \pm 0.56 \%, \mathrm{n}=24)$ did not differ significantly $(\mathrm{t}=$ $0.0975, \mathrm{df}=31, \mathrm{P}=0.923$ ). This similarity in the percentage of overwintering fertilized females in populations in different geographical areas indicates the possibility that this population characteristic is influenced by factors other than the percentage of ovipositing first-generation females. In our experimental populations, the percentage of overwintering fertilized females was influenced by the two opposing population processes discussed below.

\section{Survival of first-generation females}

The first factor influencing the difference between the percentage of ovipositing first-generation females and overwintering fertilized females was the high mortality 
of the ovipositing females in the pre-hibernation period. The cohorts established in June, with both ovipositing and non-ovipositing females, were almost completely extinct before the start of winter. Half of the ovipositing females perished in the cohorts established in July and the only female ovipositing in the August cohorts survived until winter. Thus, more than three-quarters of the ovipositing firstgeneration females died before the beginning of winter and did not contribute to the occurrence of fertilized females in the hibernating populations.

\section{Fertilization of non-ovipositing females}

The second factor influencing the difference between the frequency of ovipositing first-generation females and females overwintering in a fertilized state was the mating of non-ovipositing females. In fact, among the experimental females overwintering in a fertilized state, nearly twothirds copulated without laying eggs in the period before winter. Some of these females were observed copulating during the regular inspections of the experimental rearings. Copulations were not observed for all the females that hibernated in a fertilized state because the duration of copulation is short, typically less than one day (Honek et al., 2019). The experimental insects were checked at 2-4-day intervals, and therefore, the likelihood of copulation being observed was low. However, the circumstances in which the experimental insects were held were not natural as the females were mostly kept permanently with the same male and did not have any choice in their sexual partner. Due to these unnatural conditions, it is possible that the incidence of copulations of non-ovipositing females under natural conditions and in experiments differed and the incidence of copulations in non-ovipositing females in natural populations is unknown.

Both processes, the shortening of the life of ovipositing females and existence of fertilized females that did not oviposit, act in opposition, because as mortality decreases the fertilization of non-reproducing females increases the percentage of overwintering fertilized females. The importance of both processes in determining the percentage of fertilized females in naturally hibernating populations remains an issue that needs further study.

The conclusion is that the presence of fertilized females in a hibernating population does not correspond to the percentage of first-generation females that oviposited in the summer immediately following the imaginal moult. The effect of overwintering of fertilized females on $P$. apterus population dynamics and the possible importance of this phenomenon in spring require further research.

ACKNOWLEDGEMENTS. We thank L. Kreslova, H. Uhlirova and J. Kohoutova for excellent technical assistance. The work was supported by Institutional Support RO 0419 and grant no. QK1910281 of the Ministry of Agriculture of the Czech Republic.

\section{REFERENCES}

Altermatt F. 2010: Climatic warming increases voltinism in European butterflies and moths. - Proc. Roy. Soc. (B) 277: $1281-1287$.
Fleischer P., Fleischer P., Ferencik J., Hlavac P. \& Kozanek M. 2016: Elevated bark temperature in unremoved stumps after disturbances facilitates multi-voltinism in Ips typographus population in a mountainous forest. - Centr. Eur. For. J. 62: $15-22$.

Hodek I. 1968: Diapause in females of Pyrrhocoris apterus L. (Heteroptera). - Acta Entomol. Bohemoslov. 65: 422-435.

Hodek I. 1971: Termination of adult diapause in Pyrrhocoris apterus (Heteroptera: Pyrrhocoridae) in the field. - Entomol. Exp. Appl. 14: 212-222.

HoNĚK A. 1981: Temperature and wing polymorphism in natural populations of Pyrrhocoris apterus L. (Heteroptera, Pyrrhocoridae). —Zool. Jb. Abt. Syst. Ökol. Geogr. Tiere 108: 487-501.

HoneK A. \& MARTINKovA Z. 2019: Behavioural thermoregulation hastens spring mating activity in Pyrrhocoris apterus (Heteroptera: Pyrrhocoridae). - J. Thermal Biol. 84: 185-189.

HoneK A., Martinkova Z. \& Brabec M. 2019: Mating activity of Pyrrhocoris apterus (Heteroptera: Pyrrhocoridae) in nature. Eur. J. Entomol. 116: 187-193.

Honek A., Martinkova Z. \& Pekar S. 2020: How climate change affects the occurrence of a second generation in the univoltine Pyrrhocoris apterus (Heteroptera: Pyrrhocoridae). - Ecol. Entomol. DOI:10.1111/een.12903.

Hulle M., Bonhomme J., Maurice D. \& Simon J.C. 2008: Is the life cycle of high arctic aphids adapted to climate change? Polar Biol. 31: 1037-1042.

KIRITANI K. 2006: Predicting impacts of global warming on population dynamics and distribution of arthropods in Japan. Popul. Ecol. 48: 5-12.

KIRITANI K. 2013: Different effects of climate change on the population dynamics of insects. - Appl. Entomol. Zool. 48: 97-104.

MATEJKA K. 2019: Vývoj teplot a srážek v ČR od roku 1961. [Changes of Temperatures and Precipitations in the Czech Republic since 1961.] http://www.infodatasys.cz/climate/KlimaCR1961.htm (last accessed 19 June 2020).

Mayer P. 1874: Die Anatomie von Pyrrhocoris apterus L. Arch. Anat. Physiol. Wiss. Med. 1874: 313-347.

Musolin D.L. \& SAulich A.KH. 2012: Responses of insects to the current climate change: from physiology and behaviour to range shifts. - Entomol. Rev. 91: 3-35.

Pavan F., Floreani C., Barro P., Zandigiacomo P. \& DallaMonTA L. 2013: Occurrence of two different development patterns in Lobesia botrana (Lepidoptera: Tortricidae) larvae during the second generation. - Agric. Forest Entomol. 15: 398-406.

Pineau X., David G., Peter Z., Salle A., Baude M., Lieutier F. \& JACTEL H. 2017: Effect of temperature on the reproductive success, developmental rate and brood characteristics of Ips sexdentatus (Boern.). - Agric. Forest Entomol. 19: 23-33.

Pluot D. 1978: Donnés sur Scantius aegyptius, Hemiptère Pyrrhocoride paléarctique, comparison avec Pyrrhocoris apterus. - Ann. Soc. Entomol. Fr. 14: 703-713.

Pouvreau A. 1963: Cycle biologique et interprétation de l'arrêt de développement chez Pyrrhocoris apterus L. (Hétéroptère, Gymnocérate, Pyrrhocoridae). — Bull. Soc. Zool. Fr. 88: 180196.

Schwoerbel W. 1956: Beobachtungen und Untersuchungen zur Biologie einiger einheimischer Wanzen. - Zool. Jb. Abt. Syst. Ökol. Geogr. Tiere 54: 329-354.

SоснA R. 2010: Pre-diapause mating and overwintering of fertilized adult females: new aspects of the life cycle of the wing-polymorphic bug Pyrrhocoris apterus (Heteroptera: Pyrrhocoridae). — Eur. J. Entomol. 107: 521-525.

Socha R. \& Sula J. 1992: Voltinism and seasonal changes in hemolymph protein pattern of Pyrrhocoris apterus (Hetero- 
ptera, Pyrrhocoridae) in relation to diapause. - Physiol. Entomol. 17: 370-376.

Systat Software 2006: SigmaStat 3.5. Systat Software Inc., Point Richmond, CA, 844 pp.

Tischler W. 1959: Zur Biologie der Feuerwanze (Pyrrhocoris apterus L.). - Zool. Anz. 13: 392-396.
Vesecky A., Petrovic S., Briedon V. \& Karsky V. 1958: Atlas podnebi Československé Republiky. [Atlas of Climate of Czechoslovak Republic.] Central Administration of Geodesy and Cartography, Praha, 13 pp. + 113 maps.

Received February 18, 2020; revised and accepted June 30, 2020 Published online July 22, 2020 